\title{
Dynamic Split Tension and Energy Dissipation of Fiber Concrete Under Impact Loading Effect \\ Du Bing ${ }^{1,2, a}$ Ma Hongwei ${ }^{1, b}$ Lin Long $^{3, c}$
}

1. The MOE Key Laboratory of Disaster Forecast and Control in Engineering, College of Science \& Engineering, Jinan University, China;

2.Guangzhou Airport Entry-Exit Inspection and Quarantine Bureau, China;

3.Guangdong Traffic Investment Group Co.,Ltd, China;

aemail:dubing15@163.com, bemail:tmahw@jnu.edu.cn, cemail:451230569@qq.com

Keywords: Dynamic Split Tension; Fiber Concrete; Composite Material;SHPB; Strain Rate; Energy Dissipation

Abstract: This paper introduces a test for the dynamic split tension of fiber concrete. The dynamic-split-tension test, which used a Hopkinson bar, was performed for plain concrete, steel fiber concrete, and polypropylene fiber concrete. Test phenomena were described and analyzed. The effects of different fiber contents and strain rates on fiber-concrete split-tension strength were explored. The energy-dissipation characteristics of fiber-concrete dynamic split tension and the destruction mechanism were examined to determine the relationship between energy dissipation and releasable strain energy at high strain rates. The energy composition of fiber concrete was identified.

\section{Introduction}

Fiber-reinforced concrete is a new, multiphase composite material prepared by adding short, random-distribution fiber to ordinary concrete. Adulterating fiber added to concrete can affect the reinforcement, toughing, and crack resistance of the concrete material, as well as improve the compression resistance and tensile strength of the resulting concrete ${ }^{[1]}$. Thus, fiber reinforcement is increasingly being applied.

Fiber-concrete tensile strength is small, far less than its compressive strength; thus, the deformation and destruction of a fiber-concrete structure often depends on the fiber-concrete tensile and mechanical properties ${ }^{[2]}$. Accordingly, fiber-concrete tensile mechanical properties under impact load needs to be studied. However, because the rock direct tensile test is very difficult, an indirect tensile test is more commonly used. The dynamic-split-tension test (Brazilian disc test) is a the most widely used indirect tensile test ${ }^{[3]}$.

\section{Principle of Dynamic-Split-Tension Test}

The dynamic-split-tension test (Brazilian disk test) measures a concrete's fragile-material tensile strength. Generally, the method uses a cylinder with the same compressive-strength test as the specimen. The specimen is placed flat between the two compression plates of the testing machine, and then a concentrated pressure load is forced onto the specimen until splitting fracture occurs along the vertical plane of the active loading line. The concrete tensile strength, which is called the split-tension strength, abides by the formula of the Brazilian disc test principle. Measuring concrete tensile strength by using this test method has many advantages, including simplicity, clear principle is clear, easy operation, few errors, and reliable test data ${ }^{[4]}$. 


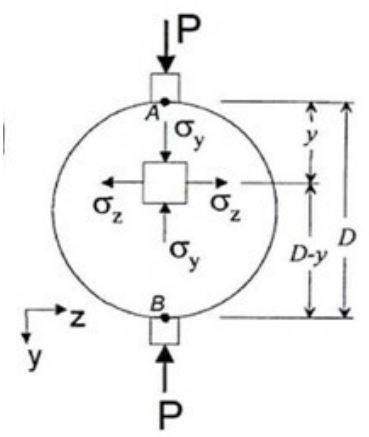

(a)

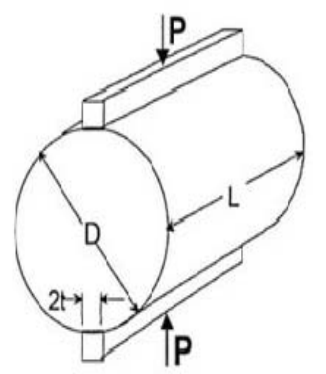

(b)

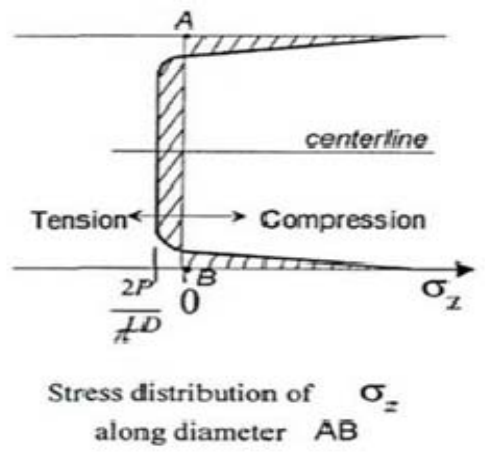

( c)

Figure 1 Split-Tension Test

Fig. 1 shows that when a uniform line-distributed external force $P$ is inflicted upon the two opposite surfaces of a cylinder specimen, the stress distribution condition inside the specimen is as follows.

1. The stress distribution with vertical diameter $A B$ is assumed to be along the load effect direction. $A$ certain unit $\mathrm{M}$ on $\mathrm{AB}$ is selected, and then a horizontal tensile stress with this unit $\mathrm{M}$ is ${ }^{[5][6][7]}$

$$
\sigma_{x}=\frac{2 P}{\pi L D}
$$

Meanwhile, the vertical pressure stress is

$$
\sigma_{y}=\frac{-2 P}{\pi L D}\left[\frac{D^{2}}{r(D-r)}-1\right]
$$

where $L$ is the length of the cylinder specimen, and $D$ is the diameter of the cylinder specimen. Equation (1) is the basic formula of the split-tension strength.

Analysis of the above equations indicate that symmetrical horizontal tensile stress is generated in the vertical middle plane of the specimen, except for the local area near the stress-application point that may generate stress concentration. When this tensile stress is increased to the fiber-concrete tensile strength, the specimen is split into half along the vertical middle plane.

Tensile strength can be calculated by the following formula:

$$
P=\pi R^{2} \sigma_{r}
$$

where $R$ is the semidiameter of an SHPB device bar, and $\sigma_{r}$ is the maximum stress when specimen destruction occurs [ $\sigma_{r}=\left(\sigma_{x}\right)_{\max }$ ].

Given that $D=2 R$, then

$$
f_{t d}=\frac{\sigma_{r} R}{L}
$$

In addition, the stress and strain rates of the fiber-concrete specimen can be estimated by the following expressions:

$$
\begin{aligned}
& \dot{\sigma}=\frac{f_{t d}}{\tau}, \\
& \dot{\varepsilon}=\frac{\dot{\sigma}}{E}=\frac{f_{t d}}{E \tau}
\end{aligned}
$$

where $\tau$ is the rising time of the transmitted wave (the time for the projecting wave to reach its maximum value), and $E$ is the elasticity modulus of the fiber concrete. 


\section{Test Part}

\section{Specimen Preparation}

The materials used for the test include clean water ( $\mathrm{pH}$ 7.1) obtained from the Civil Engineering Laboratory of Ji'nan University in Guangzhou City. The cement is ordinary silicate cement (Golden Goat Brand, Guangzhou Yuebao Cement Co., Ltd; mark number P.O42.5R). The fly ash is grade-2 fly ash (Guangzhou Huangpu Power Plant). The sand is river sand, and the gravel is granite gravel obtained manually. The water reducer is a KJ-JS Polycarboxylate High-performance Water Reducer (Guangdong Kejie Admixture Science and Technology Co., Ltd). The polypropylene and steel fibers are cold-drawn, wave-shaped steel fibers produced by Chongqing Yizhu Commerce Co., Ltd.

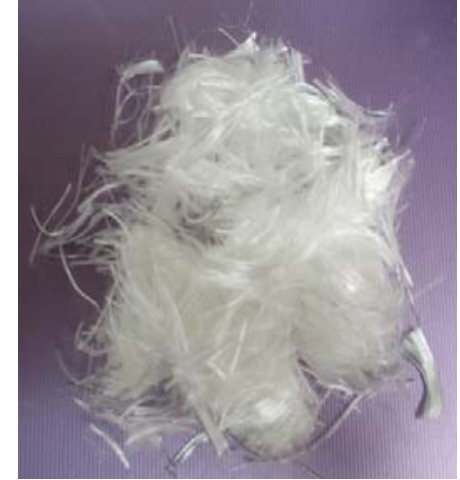

(a) Polypropylene fiber

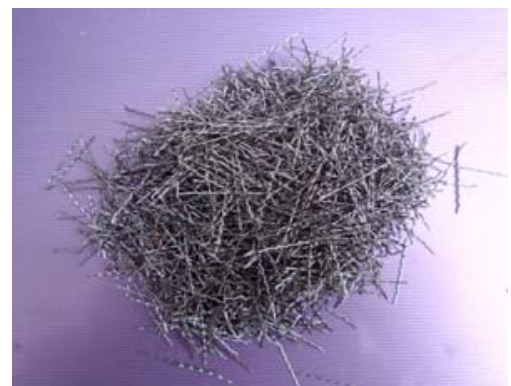

(b) Steel fiber

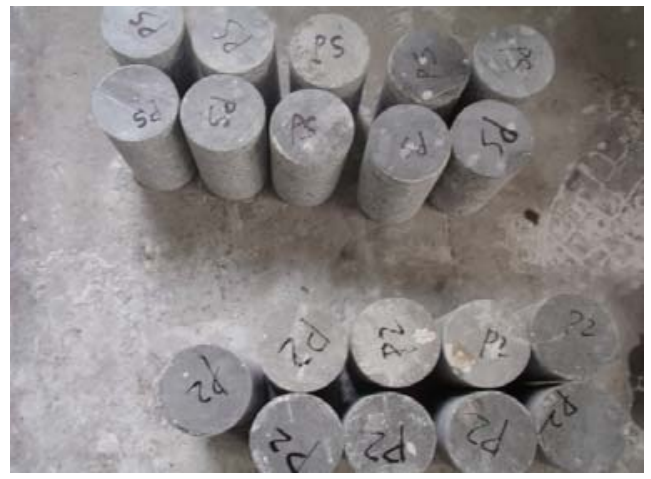

(c) Fiber concrete specimen

Figure 2 Fiber and fiber concrete specimen

Fig. 2 shows the specimen preparation carried out in the Civil Engineering Laboratory in Ji'nan University. The finished fiber-concrete specimen is shown to have undergone processing, core extraction, and cutting into shape.

\section{Dynamic-split-tension Test}

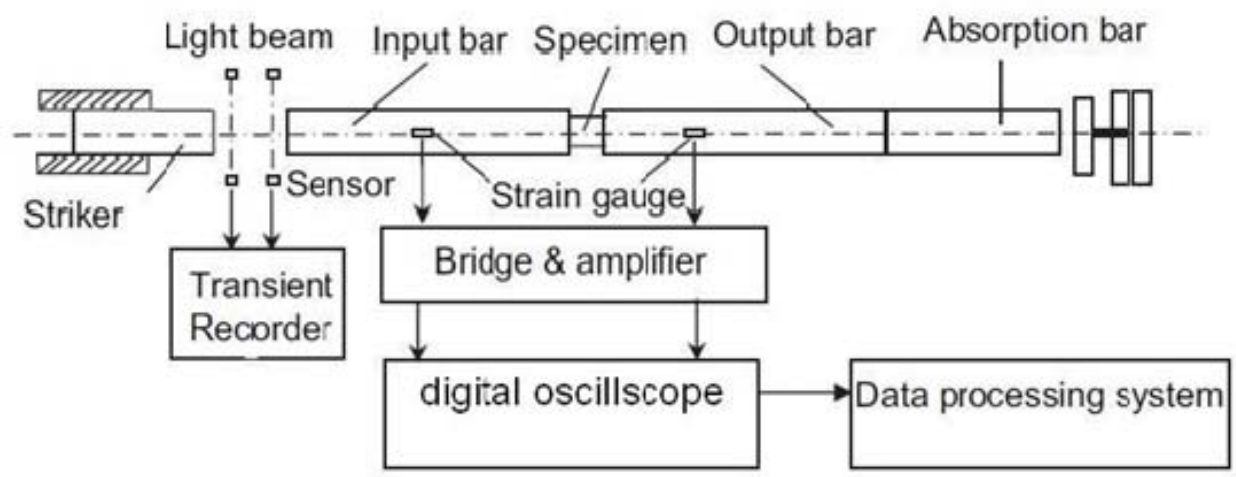

Figure 3 SHPB test facility sketch map 


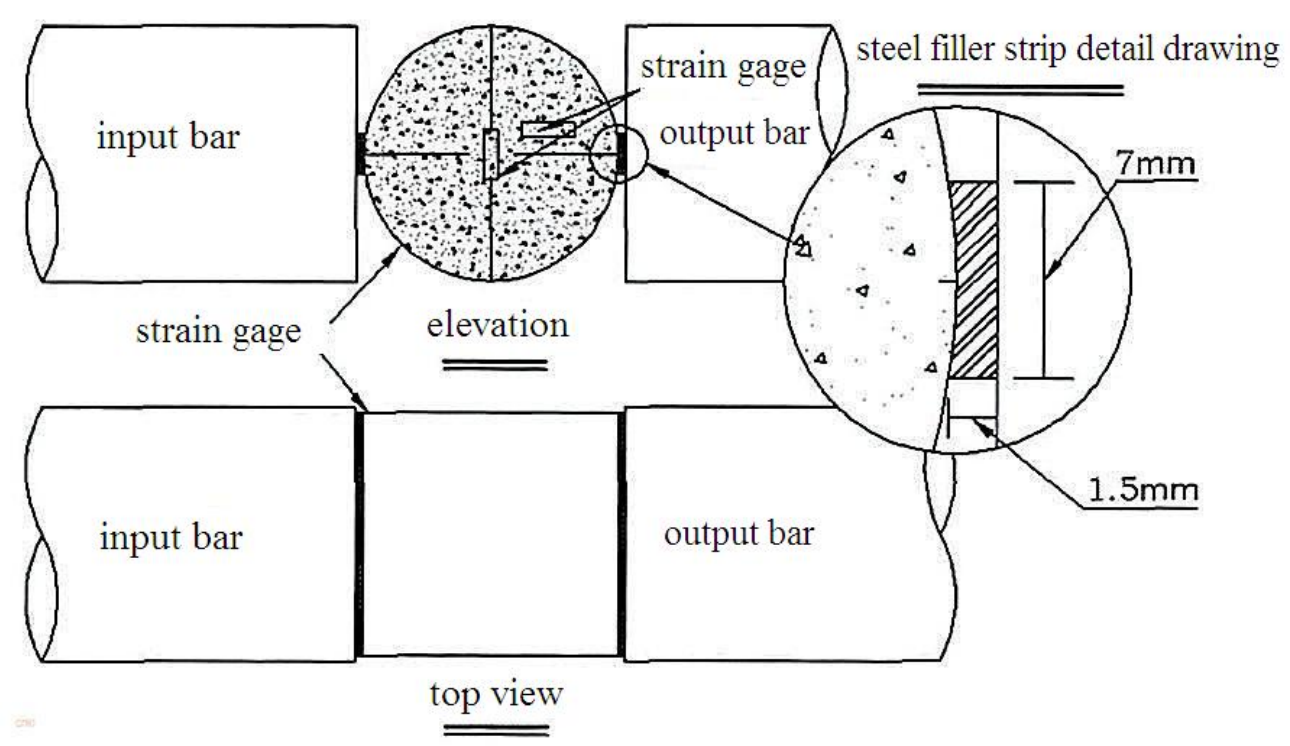

Figure 4. Specimen and steel-filler-strip design scheme

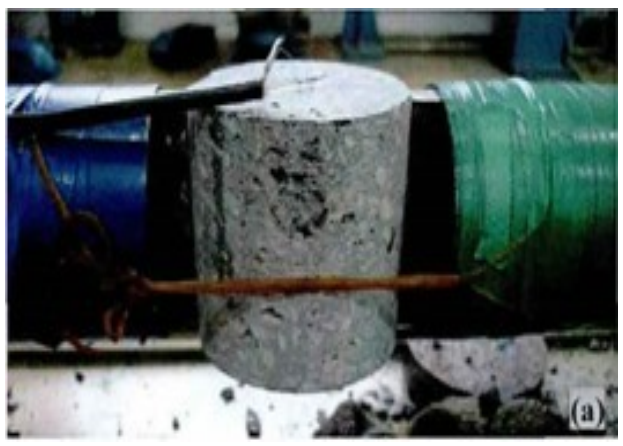

(a)

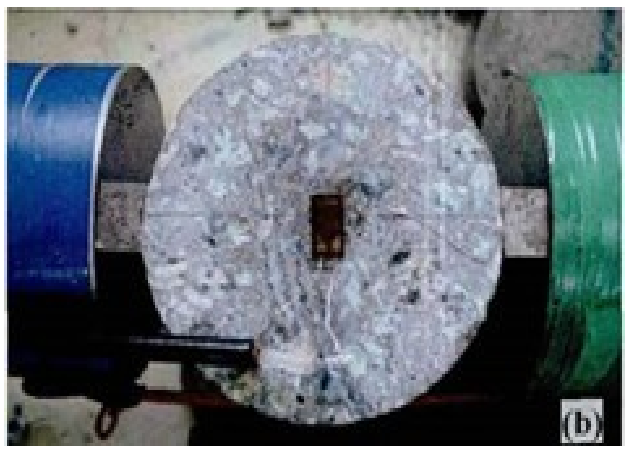

(b)

Figure 5. Specimen location during the split-tension test

Fig. 3 shows the principle of the SHPB test facility. This paper carries out dynamic-split-tension test by using a split Hopkinson pressure bar from the Concrete Structure Laboratory in South China University of Technology. The test specimen is designed according to the measurement test of the split-tension of the added filler-strip as specified by the American Society for Testing Materials. To effectively reduce the stress concentration of the bearing parts, we adopt the process shown in Figs. and 5. The arc-shaped steel filler strip is added to the contact parts among the input bar, transmission bar, and the specimen. The edge inside the filler strip presents an arc shape so that the edges of the filler strip and specimen can combine perfectly ${ }^{[8]}$.

The specimens used in this experiment are $\phi 74 \times H 74$ cylinder specimens with a strain-rate range controlled to $0-200 S^{-1}$. The specimens are grouped into six according to fiber content (including a plain concrete group). Each group consists of six cylinder specimens. Impact tests are carried out under different air pressures $(0.2,0.4,0.6$, and $0.8 \mathrm{MPa})$. During the tests, the waveforms of the incident and project waves of the pressure lever system are displayed on an oscilloscope through a superdynamic strain-indicator output. The fiber-concrete dynamic split-tension strength in the relevant stain rate is then obtained, followed by strain measurement by using the semiconductor strain gauge on the incident bar under 0.3-0.5 MPa.

SHPB split-tension tests are conducted for plain concrete, steel fiber concrete (S1) containing 1\% fiber, polypropylene fiber concretes (P1, P2, and P3 containing $0.1 \%, 0.2 \%$, and $0.3 \%$ fiber, respectively), and PS adulterated with $1 \%$ steel fiber and $0.1 \%$ polypropylene fiber. Air pressure is varied to $0.3,0.4,0.5$, and $0.6 \mathrm{MPa}$. 


\section{Analysis of Apparent Phenomena and Test Results}

After test completion, the apparent features of the specimens before and after the test are compared ${ }^{[9]}$, and the results are shown in Fig. 6.

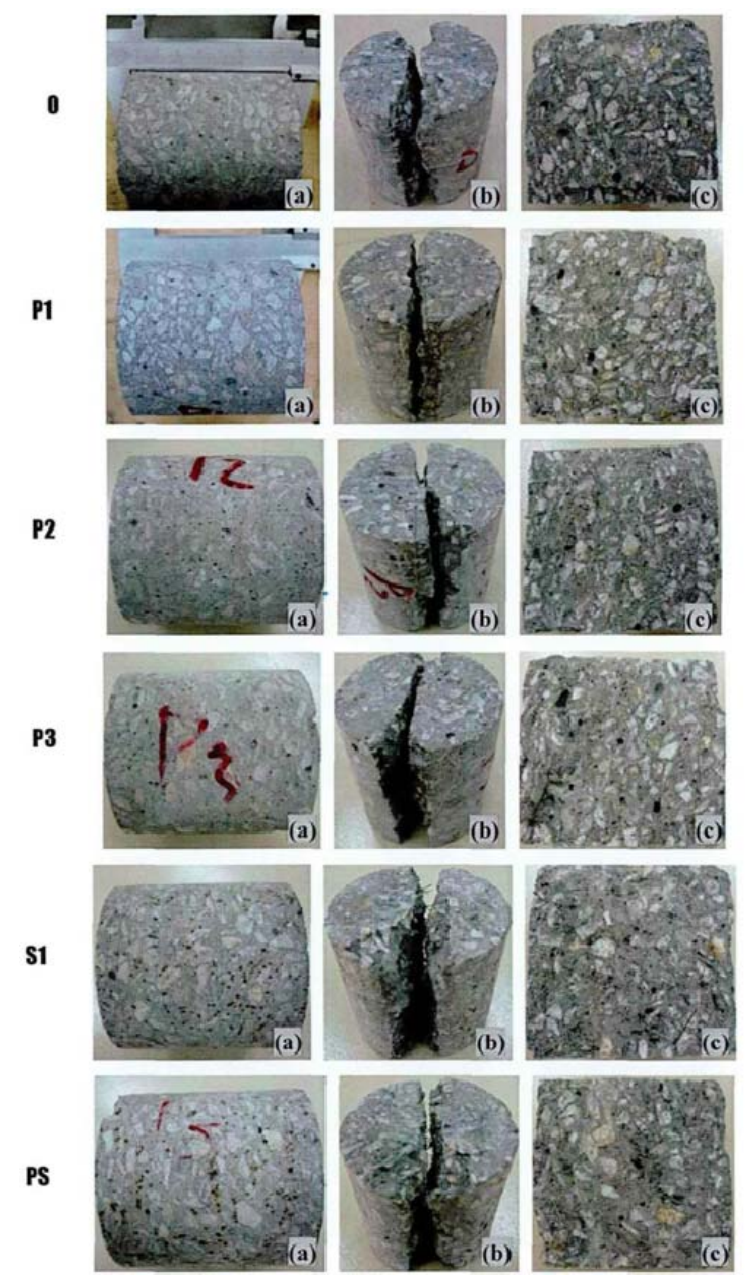

Figure 6. Comparison of apparent phenomena before and after split-tension test

At low loading speeds, the specimens are basically split into half along the center line. Some fibers of the fiber-concrete specimen are still partially connected between the two pieces. At the same time, some secondary cracks form near the specimen's main crack end. However, at 0.3 MPa air pressure, individual steel-fiber-concrete specimens do not split off.

Crack initiation and extension generally occur inside the specimen center line, and the specimen is ultimately split into half along the center line, which basically confirms the dynamic-splitting theory. However, in the test, some crack directions deviate at a certain angle to the center line, and this angle is approximately $10^{\circ}-25^{\circ}$ (Fig. 7). This finding may be due to the uneven distribution of each concrete component. At the same time, because of the loading method of the split tension, tensile and shear stresses are produced inside the concrete. Thus, the composite effect of these stresses may also be another important reason for the crack direction deviation to a certain angle compared with the center line. Meanwhile, the secondary-crack generation may be explained by the fact that after the main crack growth quickly cut through and breached the line, the tension stress is unloaded near the main crack area. Consequently, stress sharply decreases and stress concentration is generated around the end of the main crack surface. Another explanation may be that the fiber is randomly distributed in the concrete, thereby leading to crack initiation and extension along the fiber and the concrete interface. As a result, some secondary cracks are generated at the edges. 


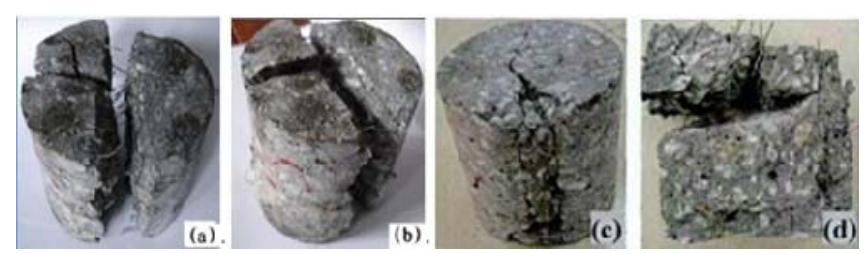

Figure 7. Abnormalities in the split-tension test

Fig. 2 shows that at high loading speed, plain concrete appears fragmented and fiber concrete crazes totally along the presplitting surface. The local area of the incidence end shows fragmentation phenomenon. Moreover, due to the poor homogeneity and symmetry of the individual specimens, some are split into three or the steel filler strip is not centered (i.e., no symmetry exists along the diameter line of the cylinder underside). Thus, the specimen is broken off at the center, as shown in the above figure.

The ratio between the dynamic- and static-split strength of fiber concrete is defined as the growth factor of the material's dynamic-split strength, which is

$$
D I F=\frac{f_{t d}}{f_{t s}}
$$

Table 1 summarizes the results of the impact split-tension test.

\begin{tabular}{|c|c|c|c|c|}
\hline $\begin{array}{c}\text { Pressur } \\
\text { e } \\
(\mathrm{Mpa})\end{array}$ & Specimen number & $\begin{array}{c}\text { Peak pressure } \\
\text { (Mpa) }\end{array}$ & Average strain rate $\left(\mathrm{s}^{-1}\right)$ & DIF \\
\hline \multirow{4}{*}{0.3} & 0 & 5.40 & 0.85 & 1.22 \\
\hline & P1 & 6.22 & 0.79 & 1.38 \\
\hline & $\mathrm{P} 2$ & 6.22 & 0.97 & 1.40 \\
\hline & P3 & 4.86 & 0.76 & 0.90 \\
\hline \multirow{6}{*}{0.4} & 0 & 18.94 & 9.25 & 3.35 \\
\hline & P1 & 19.99 & 7.62 & 3.54 \\
\hline & $\mathrm{P} 2$ & 21.04 & 7.31 & 3.72 \\
\hline & P3 & 14.73 & 5.00 & 2.61 \\
\hline & S1 & 15.78 & 7.05 & 2.79 \\
\hline & PS & 15.78 & 4.93 & 2.79 \\
\hline \multirow{3}{*}{0.5} & $\mathrm{P} 1$ & 7.30 & 3.26 & 1.62 \\
\hline & S1 & 6.76 & 2.59 & 1.20 \\
\hline & PS & 8.52 & 4.44 & 1.41 \\
\hline \multirow{6}{*}{0.6} & 0 & 15.80 & 7.05 & 2.79 \\
\hline & $\mathrm{P} 1$ & 21.10 & 14.91 & 3.73 \\
\hline & $\mathrm{P} 2$ & 14.10 & 5.51 & 2.62 \\
\hline & P3 & 21.16 & 9.72 & 3.92 \\
\hline & $\mathrm{S} 1$ & 14.53 & 6.80 & 2.57 \\
\hline & PS & 19.00 & 8.14 & 3.36 \\
\hline
\end{tabular}




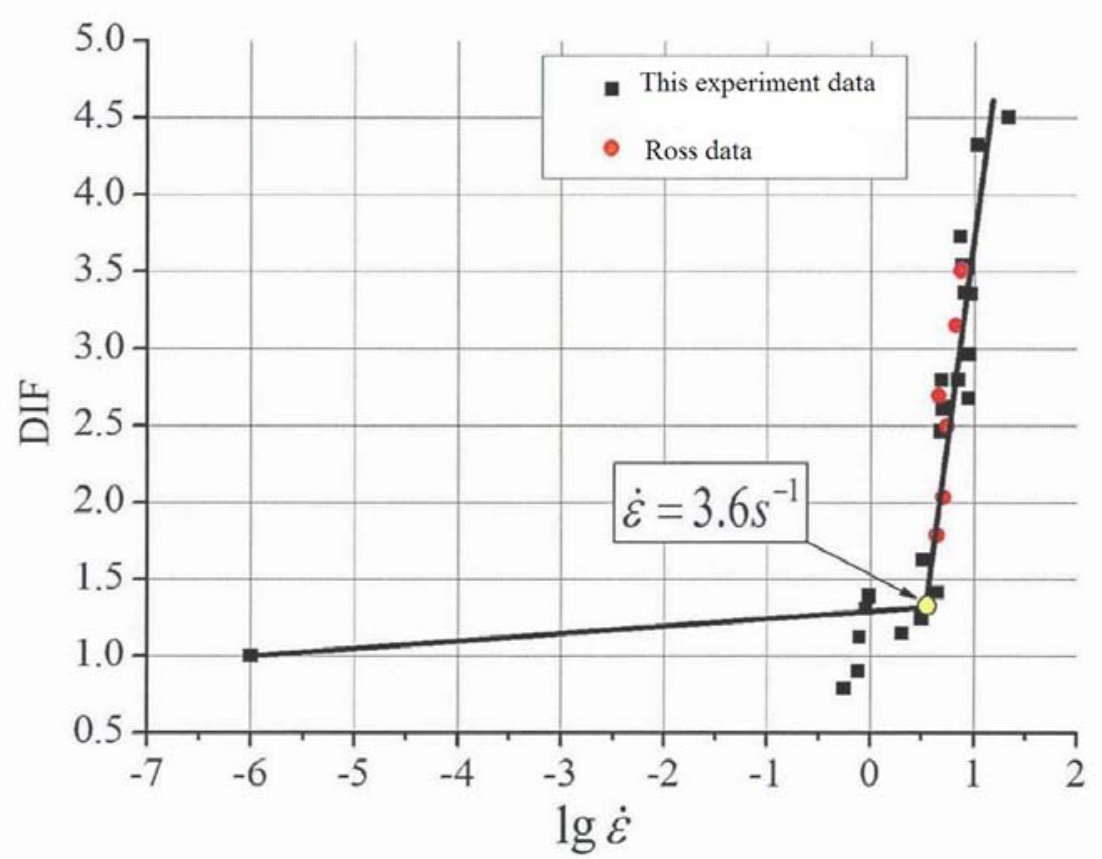

Figure 8. Relationship between relative tensile enhancement factor and strain rate

Table 1 shows that with increased strain rate, the concrete dynamic-split-tension strength increases accordingly. Figure 8 shows the fitted curve result of the test data of the present work and those of Ross ${ }^{[10][11]}$, and test points are compared. The variation trends between both test data are found to be consistent. Dynamic-split-tension strength increases with increased strain rate, and the growth factor and logarithm of the strain rate are approximated into the linear relation. The slope is around 4.0, consistent with that of Ross. Tensile strength increases with increased strain rate. When the strain rate exceeds a certain value, a larger proportion of increase is observed, indicating the existence of a critical strain rate. The strain rate threshold value is about $3.6 s^{-1}$, which has very little difference from the value obtained by Ross.

\section{Energy-Dissipation Characteristics of Dynamic-split-tension Destruction}

From the loading method, the dynamic-split-tension test inflicts pressure concentrated load in the direction of paralleling to fiber-concrete specimen presplitting surface. Axial compression deformation is generated on the presplitting surface center line, whereas tensile deformation is generated crosswise. Elastic strain energy accumulates inside fiber concrete and then transforms to lateral tensile stress. When this stress reaches the maximum tensile strength of fiber concrete, crack initiation occurs. Afterwards, elastic strain energy is quickly released, which causes the crack surface to extend rapidly.

According to the energy0dissipation characteristics of the SHPB test,

$$
\begin{aligned}
& U_{f}=U_{i}-\left(U_{r}+U_{t}\right)=U_{d}+U_{e} \\
& U_{i}=E C A \int_{0}^{t} \varepsilon_{i}^{2}(t) d t \\
& U_{r}=E C A \int_{0}^{t} \varepsilon_{r}^{2}(t) d t \\
& U_{t}=E C A \int_{0}^{t} \varepsilon_{t}^{2}(t) d t
\end{aligned}
$$

where $U_{f}$ is accumulated energy in the fiber-concrete specimen; $U_{i}, U_{r}$, and $U_{t}$ are the incident, reflected, and transmitted wave energies, respectively; $A$ and $E$ are the cross-section area and the elasticity modulus of the pressure lever, respectively; $C$ is the one-dimensional stress wave elasticity wave velocity of the pressure lever; $U_{d}$ and $U_{e}$ are the damaging dissipation energy and the 
releasable elastic strain energy of the fiber-concrete specimen, respectively; and $E$ is the unloading elasticity modulus.

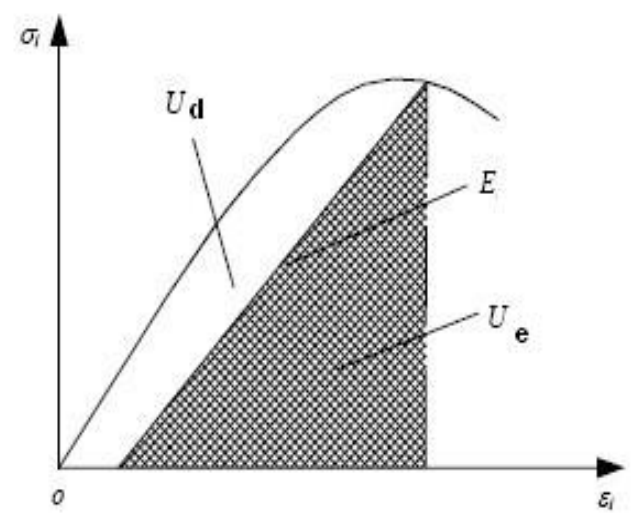

Figure 9 Relationship between energy dissipation and releasable strain energy at high strain rates

Figure 9 shows the stress-strain curve of the fiber-concrete specimen. Area $U_{d}$ represents the consumed energy when a part of the initial crack appears, a part of the original crack extends, and a part of the bond stress between fiber and concrete interface is overcome. The shaded area $U_{e}$ represents the releasable elastic strain energy stored in the fiber concrete unit. The energy of this part is the released elastic strain energy when the fiber concrete unit unloads and is mainly used as the launching kinetic energy of the concrete specimen's flying-out fragment, as well as other energy dissipation types (acoustic energy, thermal energy, etc.). The appearances of the initial crack in the concrete specimen fragment, the extension of the partial original crack, and the consumed energy used to overcome the partial bond stress between fiber and concrete interface are observed. Meanwhile, the polypropylene fiber concrete, also includes the consumed energy to overcome the tensile stress of polypropylene fiber.

The above-mentioned damaging dissipated energy and releasable elastic strain energy can be explained by the fact that under impact load, when the strain rate is too high inside the fiber concrete, the transient high stress compels part of the fiber concrete unit to generate damage. The partial bond stress between the fiber and concrete interface is lost, and then fiber concrete strength is reduced. When the vast elastic strain energy is stored and accumulates inside most of the fiber concrete unit, the damaging dissipated energy is small. This phenomenon is the main difference between the dynamic and static destruction of fiber concrete. During the plastic deformation of concrete, the crack damages the concrete interior, and the bond stress between the concrete and fiber interface is overcome. This result is due to the damaging dissipated energy $U_{d}$ and to the partial releasable elastic strain energy $U_{e}$. When the elastic strain energy stored inside the fiber concrete in a short time surpasses the interface energy of the fiber concrete, transient general demolition of the fiber-concrete specimen and burst dynamic destruction of the multifragment occur.

When in the static state, a low strain-rate loading is observed. The increased external work gradually dissipates and generates new damages. This damage is extended, and the fiber and concrete interface bond stress is overcome. Plastic deformation of fiber concrete occurs, the crack damages the concrete interior, and the energy to overcome the bond stress between the concrete and the fiber interface originates mainly from the damage dissipated energy $U_{d}$. Meanwhile, the releasable elastic strain energy stored in the unit is small. When the external applied load is close to the ultimate strength, the elastic strain energy stored in the remaining unit after the damage exceeds the unit surface energy, thereby inducing the fiber concrete to generate general demolition. 


\section{Energy Constitution of Fiber Concrete Dynamic-split-tension Specimen}

From the energy perspective, the deformation and fracture of fiber concrete are processes where energy is accumulated, dissipated, and released ${ }^{[16]}$.

The accumulated energy $U_{f}$ in the fiber-concrete specimen is mainly composed of three parts. First is the broken energy dissipation $U_{F D}$, which is mainly used to generate the initial crack of the concrete specimen, to extend the original crack, to generate and extend the microcrack in the fragment, and to produce the consumed energy needed to overcome the bond stress between the fiber and concrete interface. As for the polypropylene fiber concrete, it also includes the dissipated energy to overcome the tensile stress of this fiber. Second, is the launching kinetic energy $U_{K}$ of the fiber concrete fragment. Third and last is the dissipated energy $U_{E}$, which exists in various forms such as thermal energy, etc. Thus,

$$
U_{f}=U_{F D}+U_{K}+U_{E}
$$

The energy consumption $U_{E}$ is generally believed to be very small as to be negligible. Thus,

$$
U_{f}=U_{F D}+U_{K}
$$

In the Hopkinson bar impact test, especially under high strain-rate loading conditions, each fragment launching speed of the fiber-concrete specimen is very difficult to measure. Thus, confirmation of the existence of $W_{K}$ is also difficult. Zhang $\mathrm{Z} \mathrm{X}$ et al. ${ }^{[12]}$ measured the fragment flying speed in the SHPB test by using a high-speed photography camera to calculate the launching kinetic energy $W_{K}$ of the specimen flying fragment. Hong Liang ${ }^{[13]}$ analyzed SHPB test results and found that $W_{F D}$ is $\sim 95 \%$ of $W_{K}$ with a strong linear relationship, whereas $W_{K}$ accounts for only about $5 \%$ of $W_{F D}$.

Thus, in the SHPB test, the energy absorbed by the fiber-concrete specimen occurs in the vast majority during the generation and extension of the microcrack. Moreover, the energy $W_{F D}{ }^{[14][15]}$ is that needed to overcome the bond stress between fiber and concrete, as well as to cause the specimen to lose stability and be damaged. It can be replaced by the following formula:

$$
\begin{aligned}
& W_{f}=\eta W_{F D} \\
& W_{F D}=W_{F D 1}+W_{F D 2}+W_{F D 3}+W_{F D 4}+W_{F D 5}
\end{aligned}
$$

where $W_{F D 1}$ is the dissipated energy of a certain slipping crack growth; $W_{F D 2}$ is the dissipated frictional energy when a certain initial crack surface slips; $W_{F D 3}$ is the dissipated energy needed to overcome the bond stress between the fiber and the concrete interface; $W_{F D 4}$ is the dissipated energy needed to overcome the fiber bridge linking effect; and $W_{F D 5}$ is the dissipated energy needed to overcome the fiber tensile stress.

\section{Conclusions}

Five main conclusions are drawn from the above analysis. First, fiber concrete generates splitting based on the presplitting surface direction, consistent with the theoretical result. Second, fiber concrete split-tension strength exerts an obvious strain-rate effect. Third, fiber content has a reinforcing effect on concrete tensile strength, among which steel-fiber-concrete average enhancement factor has the maximum effect. With increased fiber content, the damage degree of polypropylene fiber concrete decreases, and a higher quantity of adulterant added to polypropylene fiber concrete results in higher average tensile strength enhancement factor. Fourth, relative tensile enhancement factor has a positive correlation with strain rate. Fifth and last, the energy-dissipation characteristics of the dynamic-split-tension fracture can effectively reflect the dynamic-split-tension fracture mechanism of fiber concrete under the SHPB test condition. 


\section{Acknowledgements}

This work

was

financially

supported

by

the China National Science Funding (11390362) and opening foundation for State Key Laboratory of Beijing Institute of Technology Explosion Science and Technology ( 33810005).

\section{References}

[1] Hannant D J.Fiber cements and fiber concretes [M] .New York: Wiley, 1978

[2] Fei Yang, Hongwei Ma, Jing Lin, Longmao Zhao, etc. Latin American Journal of Solids and Structures, 2015.12 (4) .730-746

[3] ISRM Testing Commission Suggested method for determining tensile strength of rock materials [J] International Journal of Rock Mechanics and Mining Sciences and Geomechanics Abstracts, 1978,15 (3):. 99-103.

[4] C.Liu. Experimental Mechanics. 2010.50 (7) .1025-1039

[5] Shaolin Zhao. Journal of Changsha Railway University,1979.2:63-79(In Chinese)

[6] Weijing Niu, Xiaopeng Run,Lijun Zhang, Hongwei Ma. Journal of Taiyuan University of Technology, 2006(37):239-240. (In Chinese)

[7] Abbass Tavallali, Andre Vervoort.Journal of Rock Mechanics and Geotechnical Engineering 2013 (5): 366-377

[8] Ma hong-wei, Zhang li-jun, Yan xiao-peng, Cheng zai-bin. PhD, TUDelft, Netherlands, 1997.

[9] Lin Long. Fiber Concrete Dynamic Property Test Research Under Impact Load Effect [D]. Guangzhou: Ji’nan University, 2011. (In Chinese)

[10] Ross CA, Tedesco JW, Kuennnen S T. 1995; 92 (1): 37-47

[11] Tedesco JW, Ross C A. Journal of Pressure Vessel Technology 1998, 120: 398-405

[12] ZX Zhang, SQ Kou, LG Jiang, P.-A. International Journal of Rock Mechanics and Mining Sciences 2000 (37): 745- 762(In chinese)

[13] Hong Liang. Rock Strength and Crushing Energy Dissipation Characteristics Size Effect Under Impact Load Research [D]. Changsha: Central South University, 2008(In Chinese)

[14] Ravichandran G, Subhash G .International Journal of Solids and Struetures, 1995, 32 (17/18): $2627-2646$

[15] ZX Zhang, SQ Kou, etc. International Journal of Rock Mechanics and Mining Sciences 2000,37: $745-762$

[16] Torabi AR, Campagnolo A, Berto, F. Materials \& design 2014 (69):22-29 